Научная статья

УДК 373.31

DOI: $10.18101 / 2307-3330-2021-4-45-52$

\title{
ФОРМИРОВАНИЕ ЧИТАТЕЛЬСКОЙ ГРАМОТНОСТИ НА УРОКАХ ЛИТЕРАТУРНОГО ЧТЕНИЯ В НАЧАЛЬНОЙ ШКОЛЕ
}

\section{(C) Гаврилова Светлана Михайловна}

учитель начальных классов,

Агинская средняя общеобразовательная школа № 2

Россия, 687000, п. Агинское, пер. Майский, 8

svetlana70gavrilova@mail.ru

\section{(C) Дондокова Римма Батомункуевна}

кандидат педагогических наук, доцент,

Бурятский государственный университет имени Доржи Банзарова

Россия, 670000, г. Улан-Удэ, ул. Смолина, 24а

dondokova64@mail.ru

Аннотация. В статье представлены материалы по формированию читательской грамотности младших школьников. В современных условиях читательская компетентность младших школьников позволяет заложить основы успешности в дальнейшем обучении и будущей взрослой жизни. Фундаментальная роль чтения в современной системе образования и развития школьников общеизвестна, так как полноценная грамотность, начитанность всегда выступали одним из необходимых компонентов любой деятельности, связанной с восприятием и осознанием визуальной информации. Развитие новых информационных технологий только повышает значимость чтения в обществе. Овладение приемами работы с текстом происходит параллельно с освоением новых форм представления знаний, связанных со считыванием и переработкой информации.

Уроки литературного чтения предоставляют большие возможности для формирования читательской грамотности. Автор статьи делится своим педагогическим опытом по организации уроков литературного чтения в начальных классах. Описаны технология продуктивного чтения и различные методические приемы, позволяющие понимать текст, размышлять над его содержанием, оценивать его смысл и значение, фиксировать и использовать полученную информацию, излагать свои мысли о прочитанном.

Ключевые слова: чтение, читательская грамотность младших школьников, литературное чтение, технология продуктивного чтения, методические приемы, компетенции, базовые компетенции, педагогическая деятельность.

\section{Для цитирования}

Гаврилова С. М., Дондокова Р. Б. Формирование читательской грамотности на уроках литературного чтения в начальной школе // Вестник Бурятского государственного университета. Образование. Личность. Общество. 2021. № 4. С. 45-52. 
Ступень начального образования предъявляет серьезные требования к развитию младшего школьника, способного к взаимодействию с окружающим миром, самообразованию и личностному росту. В этой связи огромное значение приобретает важность уроков литературного чтения. Формирование читательской грамотности детей происходит в постоянном расширении образовательных и воспитательных возможностей данных уроков.

Чтение - основной и ничем не заменимый источник социального опыта прошлого и настоящего, важнейший способ освоения базовой социально-значимой информации. Умение грамотно читать, адекватно воспринимать полученную информацию, постигать смысл текста является базовым для младших школьников.

В реальной жизни и родители и учителя жалуются, что дети не хотят и не любят читать! Мы задумались над этой проблемой, попытались найти пути решения.

Задача формирования читательской грамотности младших школьников актуализировалась также с введением ФГОС. Основой Федеральных государственных образовательных стандартов второго поколения становится формирование базовых компетентностей современного человека:

- информационной: умение искать, анализировать, преобразовывать, применять информацию для решения проблем;

- коммуникативной: умение эффективно сотрудничать с другими людьми;

- самоорганизации: умение ставить цели, планировать, ответственно относиться к здоровью, полноценно использовать личностные ресурсы;

- самообразования: готовность конструировать и осуществлять собственную образовательную траекторию на протяжении всей жизни, обеспечивая успешность и конкурентоспособность;

- развития критического мышления: умение доказывать, рассуждать, опровергать;

- развития креативности;

- умение произвольно управлять собственным поведением, подчинять его сознательному контролю, преодолевать импульсивность ${ }^{1}$.

Наиболее сензитивным периодом для формирования читательской грамотности является младший школьный возраст. В данный возрастной период происходит интенсивное развитие ребенка, формируется читательская грамотность.

Литературное чтение - особый предмет школьной программы 1-й ступени образования. Оно создает условия для успешности обучения по всем предметам и является фундаментом для всего последующего обучения читателя, способного самостоятельно добывать знания, обладающего основным умением - умением учиться. Успешность изучения курса литературного чтения обеспечивает результативность обучения по другим предметам начальной школы.

${ }^{1}$ Федеральный государственный образовательный стандарт основного общего образования. Москва: Просвещение, 2013. 
С. М. Гаврилова, Р. Б. Дондокова. Формирование читательской грамотности на уроках литературного чтения в начальной школе

В. А. Левин автор книги «Когда маленький школьник становится большим читателем» пишет: «Художественное развитие мы понимаем как одно из необходимых условий становления человека современной культуры, самостоятельно строящего свою жизнь и отвечающего за свои поступки перед людьми и совестью. В наших условиях человек редко овладевает художественной деятельностью стихийно, спонтанно. Для приобщения к искусству нужна специальная педагогическая организация жизни ребенка» [1].

Суть работы учителя - организовать полноценное восприятие детьми тех произведений, которые они читают. В процессе обсуждения случаев из жизни героев, рассуждений над их взаимоотношениями с людьми, природой, выяснений важных жизненных вопросов младшие школьники знакомятся с некоторыми наиболее важными законами мира, с закономерностями, у них формируется отношение к окружающему миру, к людям, к труду.

Современные дети в жизни сталкиваются с довольно сложными проблемами. Чем раньше они начнут задумываться об истоках любви и ненависти, порядочности, добра, тем лучше. Чувство участия, сопереживания воспитывают гораздо лучше, чем назидания и нравоучения со стороны взрослых. Многие педагоги считают, что у ребенка младшего школьного возраста нет необходимых жизненных наблюдений, обобщений, эмоциональных переживаний. Опыт работы в школе показывает, что жизненный опыт ребенка, который достаточно богат и насыщен к школьному возрасту и на это нужно опираться на уроках литературного чтения.

Проведя анализ учебников по литературному чтению в начальной школе, мы делаем вывод, что имеющегося содержания достаточно. Авторы учебников подобрали достаточно хороших материалов для обучения, развития и воспитания младших школьников, но этот материал учителям качественно надо подавать. Авторами подобраны хорошие тексты, но методические рекомендации направлены на поверхностный неглубокий анализ, основанный на недоверии в возможности ребенка младшего школьного возраста, ориентированного на некоего усредненного ученика, не выходящей за пределы актуального развития ребенка. А чтобы добиться реального воспитательного эффекта, чтобы произошло проживание этого опыта, эмоциональное осмысление, надо построить работу с текстом на пределе возможного, т.е. в «зоне ближайшего развития» (Л. С. Выготский).

Учителя начальных классов хорошо знают, как традиционная методика предлагает работать с новым текстом на уроке. Сначала учитель готовит ребенка к восприятию текста: рассказывает о писателе, тематике его произведений, затем объясняет значение непонятных (с его точки зрения) слов, которые он сам заранее выписал из текста, потом (опять же сам) выразительно читает текст вслух, и только после этого к работе приступают дети: читают вслух, отвечают на вопросы учителя. Получается, что текст, который дети должны учиться читать, уже прочитан учителем. В результате деятельность детей не мотивирована и им неинтересно. Более того, им не ясно, почему нужно отвечать именно на эти вопросы, как они задаются, по какому принципу. По сути дела, дети не получают ответа на главный вопрос: что же значит читать текст? Не получают удовольствия от самого процесса чтения, уже нет никакой интриги, загадки, потому и процесса чтения как такового нет. Отсюда - скука на уроке, нелюбовь к чтению. 
За последнее время многое изменилось в школе, появилась необходимость изменить подход к урокам литературного чтения. Нужно чтобы дети умели эмоционально реагировать, проживать, переживать, глубоко мыслить. Чтобы духовно-нравственные ценности стали внутренним достоянием, духовным богатством и характеристикой личности. «Чтобы переварить знания, надо поглощать их с аппетитом» - писал Анатоль Франс

Ведь главная цель чтения литературных, художественных произведений воспитать интерес и любовь к книге, к произведению, к автору, а для этого ребенок должен понимать и чувствовать, что в этой книге есть какая-то тайна, неожиданный поворот сюжета, глубокий скрытый смысл, что чтение этого текста откроет какую-либо загадку, истину о жизни, о людях, о природе, о любви, о дружбе, об истоках добра, справедливости. Ребенок должен сделать свое маленькое, пусть даже незначительное открытие от каждого текста, произведения, открыть те нюансы, о которых ребенок не знал, не понимал, хотя возможно и догадывался ранее. Чтение книги - это всегда встреча с неожиданным, это всегда открытие. Только это создает интригу, тем самым вызывает особый интерес к чтению, может дать ребенку духовно-нравственный потенциал

Решением этой проблемы является технология формирования типа правильной читательской деятельности: технология продуктивного чтения. Данная технология обеспечивает понимание текста за счет овладения приемами его освоения на этапах до чтения, во время чтения и после чтения. Эта технология направлена на формирование коммуникативных универсальных учебных действий, обеспечивая умение истолковывать прочитанное и формулировать свою позицию, адекватно понимать собеседника (автора), умение осознанно читать вслух и про себя тексты учебников; познавательных универсальных учебных действий, например, - умения извлекать информацию из текста [2].

Конечно, опора на технологию продуктивного чтения не означает, что уроки работы с текстом должны быть однообразны по своей структуре и организации.

\begin{tabular}{|l|l|}
\hline \multicolumn{2}{|l|}{ Сравнение традиционного урока с уроком по технологии продуктивного чтения } \\
\hline Традиционный урок чтения & $\begin{array}{l}\text { Урок с применением технологии продуктивного } \\
\text { чтения }\end{array}$ \\
\hline \multicolumn{2}{|c|}{ До чтения } \\
\hline $\begin{array}{l}\text { Учитель готовит детей к восприя- } \\
\begin{array}{l}\text { тию текста. Например: сегодня я } \\
\text { расскажу вам о писателе }\end{array}\end{array}$ & $\begin{array}{l}\text { Ученики прогнозируют содержание текста. } \\
\text { Например, предположите, о чем этот текст, по его } \\
\text { названию. А иллюстрация подтверждает это? (та- } \\
\text { ким образом возникает мотивация к чтению) }\end{array}$ \\
\hline \multicolumn{2}{|c|}{ Во время чтения } \\
\hline $\begin{array}{l}\text { Учитель сам читает вслух, дети } \\
\text { слушают }\end{array}$ & $\begin{array}{l}\text { Ученики читают и ведут диалог с автором, за- } \\
\text { дают вопросы, прогнозируют ответы, проверяют } \\
\text { себя по тексту. } \\
\text { (Возникает читательская интерпретация) }\end{array}$ \\
\hline \multicolumn{2}{|c|}{ После чтения } \\
\hline $\begin{array}{l}\text { Ученики отвечают на вопросы учи- } \\
\text { теля, перечитывают текст, по зада- } \\
\text { ния учителя. }\end{array}$ & $\begin{array}{l}\text { Ведется беседа с детьми, в ходе которой уточня- } \\
\text { етсяция автора. }\end{array}$ \\
\hline
\end{tabular}


С. М. Гаврилова, Р. Б. Дондокова. Формирование читательской грамотности на уроках литературного чтения в начальной школе

В данной технологии появляется новый прием: диалог с автором - это прием работы с текстом во время его чтения. С точки зрения сформировавшегося читателя - это естественная беседа с автором через текст.

Чтобы диалог был содержательным и полноценным, читателю необходимо по ходу чтения совершать разнообразную работу: находить в тексте прямые и скрытые авторские вопросы, задавать свои вопросы, обдумывать предположения о дальнейшем содержании текста, проверять, совпадают ли они с замыслом автора, т.е. включать воображение. Психологи говорят о том, что во время диалога с автором происходит вычитывание информации из каждой единицы текста, вероятностное прогнозирование нового содержания, самоконтроль своих прогнозов и предположений.

Как научить детей вести диалог с автором? Конечно, способность, читая, вести диалог с автором через текст редко, когда возникает самостоятельно у современных детей. У большинства учащихся ее необходимо формировать в процессе совместного чтения текста учителя с детьми. Это может происходить и во время первичного чтения, и во время перечитывания - все зависит от особенностей текста. Это вопросы, ответы на которые содержатся в тексте, но в неявной, скрытой форме: чем это можно объяснить? Что из этого следует? Что сейчас случится? Почему именно так...? Для чего ...? Кто такой ...?

Возникающие вопросы, предполагают возникновение ответов-предположений и проверку себя по ходу дальнейшего чтения. Учитель старается научить ребят видеть в тексте авторские вопросы, прямые и скрытые.

В начальной школе огромную роль в воспитании играют уроки литературного чтения, включая и внеклассное чтение. Воспитание бесполезно, если оно не затрагивает эмоции человека. Главная проблема! Это то, что не используется воспитательный и нравственный потенциал литературных источников, с которыми знакомятся дети в начальной школе! Почему возникла необходимость что-то менять, что-то предлагать новое, иное, другое? Что существует на данный момент, не удовлетворяет, не достигает цели, существующая практика не решает в полной мере эту проблему!

Мы предлагаем механизмы формирования грамотного читателя. «Технология проблемного диалога» применяется мной и на уроках литературного чтения. При применении технологии проблемного диалога, роль учителя - координирующая, направляющая. Тексту отводится приоритетная роль - его читают, анализируют, трансформируют. По тексту дискутируют, сочиняют.

Прием «Противопоставление фактов», «Антиципация» (предвосхищение, предугадывание), «Проблематизация», «Чтение-сканирование» (Чтение с пометками, чтение с выделением ключевых слов), «Узелки на память» - для наилучшего запоминания изучаемого материала, на этапе рефлексии детям предлагается «завязать узелки на память) (Это могут быть карточки, какие-то значки или просто - загибаем пальчики).

Неважно, где растет ребенок. Ведь любой уголок России всегда гордится чем - то своим, неповторимым. Учителю важно осознать, что наравне с полученными знаниями о своем крае ученик должен испытывать чувство гордости за свою малую родину, ее неповторимость, осознать себя ее частью и как следствие почувствовать желание сохранить ее уникальность, продолжить традиции предков. 
На уроках школьники, работая парами или группами - учатся работать сообща, вкладывая в общее дело что - то свое, прислушиваясь к мнению одноклассников. Потом им будет легче строить свои отношения в семье, в рабочем коллективе.

Воспитывая подрастающее поколение необходимо создавать ситуации, способствующие эмоциональному восприятию полученных знаний. Их осознанию и применению на практике. Эмоциональная восприимчивость во многом определяет умение сочувствовать. Один из способов создания таких ситуаций - специально организованные занятия, формы проведения которых разнообразны: беседы, экскурсии, тренинги, праздники и т.д.

Л. А. Ефросинина - автор учебника «Литературное чтение» программы «Начальная школа XXI века» предлагает разные отдельные техники «проникновения» в смысл текста, овладения его содержанием. «Тщательное», устоявшееся чтение основывается на приобретении ряда способов, связанных с анализом содержания и формы текста. К таким техникам относятся:

- «тщательное» чтение с выделением «точек предпонимания» (Г.-Г. Гадамер) текста (работа на этапе первичного восприятия текста, выяснение того, что непонятно, что показалось странным, необычным; именно в «точках предпонимания» можно уловить зачатки будущих «гипотез смысла», которые рассматриваются в ходе анализа);

- чтение текста «островками» (В. В. Розанов) - неторопливое чтение с остановками и пояснением прочитанного фрагмента, установление связок между разными точками зрения читателей и выявлением самых ярких мест для понимания содержания произведения;

- составление «вопросника» к новым изучаемым текстам, на его основе формулирование учебной задачи урока;

- организация «диалога» автора и читателей через систему поставленных $\kappa$ тексту вопросов, выявляющих эмоционально-ценностные ориентации, предмет разговора и особенности «языка» текста;

- чтение с иллюстрированием;

- чтение с переводом с языка литературы на язык театра, кинофильма (распределение ролей, чтение по ролям, драматизация текста);

- выделение выбранного фрагмента, наиболее ярко иллюстрирующего замысел автора, его точку зрения на проблему; соотнесение своей позиции с позицией автора и других читателей;

- прогнозированное чтение (во время чтения текста произведения учитель делает остановку («обрыв») и опускает одно из событийных звеньев, чаще всего финальное, нарушая тем самым привычный для читателя ритм формирования эстетического объекта. Читатель вынужден самостоятельно, опираясь на факты художественной реальности и на показатели собственного переживания, заполнить сюжетные «пустоты»).

В младшем школьном возрасте мы начинаем закладывать основы культуры мира у каждого ребенка. Для ребенка духовным центром, нравственным основанием является семья, ее ценности, устои, отношения, семейный уклад. Эффективность воспитательной работы учителя во многом зависит от его умения находить 
С. М. Гаврилова, Р. Б. Дондокова. Формирование читательской грамотности на уроках литературного чтения в начальной школе

общий язык с родителями, опираясь на их помощь и поддержку, так как семья оказывает значительное влияние на развитие личности ребенка.

По мнению В. А. Сухомлинского, задача педагога сделать родителей своими союзниками в деле воспитания и обучения детей. «Только вместе с родителями, общими усилиями, учителя могут дать детям большое человеческое счастье».

Применяемая нами форма работы с родителями - это Родительские чтения. Одна из форм педагогической поддержки, способ вернуться к добрым традициям духовно-нравственного воспитания.

Родительские чтения - это просветительское мероприятие для родителей, в основе которого лежит чтение конкретной литературы (отрывков из нее, отдельных cmaтей) по вопросам родительского образования. Это возможность обменяться друг с другом опытом семейного воспитания. Родительские чтения предоставляют педагогу и родителям согласовать общие понятия в деле воспитания детей, что способствует взаимопониманию образовательного учреждения и семьи, педагога и родителя, родителей и ребенка.

Таким образом, приходим к выводам:

- Эффективность уроков литературного чтения в начальной школе зависит, прежде всего, от учителя, задача которого - выступить организатором учебной деятельности, стать соучастником этого процесса. Тогда он уверенно может сказать:

«Мои ученики будут узнавать новое не только от меня; они будут открывать это новое сами» (И. Г. Песталоцци).

- Необходимо обеспечить на уроках чтения эмоциональное восприятие прочитанного произведения: сопереживание героям, заинтересованное обсуждение прочитанного. Читая, ученики делают маленькие открытия.

- Работа по формированию грамотного читателя будет более эффективной, если в ней примут непосредственное участие родители учеников. Использовать различные формы работы с родителями: традиционные и нетрадиционные.

Лuтература

1. Левин В. Когда маленький школьник становится большим читателем. Москва: Просвещение, 1994. 161 с. Текст: непосредственный.

2. Бунеева Е. В., Яковлева М. А. Методические рекомендации для читателя. Москва: Просвещение, 2003. С. 407. Текст: непосредственный.

3. Бунеев Р. Н., Бунеева Е. В. Тетрадь по литературному чтению 3-й класс. Москва: Просвещение. 2014. С.11-12. Текст: непосредственный.

Статья поступила в редакиию 02.10.2021; одобрена после рецензирования 13.10.2021; принята к публикации 15.12.2021.

\section{READER LITERACY FORMATION IN LITERARY READING LESSONS IN PRIMARY SCHOOL}

Svetlana M. Gavrilova

primary school teacher

Aginskaya Secondary School № 2

8 Lane Maysky, Aginskoye, 687000 Russia

svetlana70gavrilova@mail.ru 
Rimma B. Dondokova

Candidate of Pedagogical Sciences, Associate Professor

Dorzhi Banzarov Buryat State University

24 a Smolina St., Ulan-Ude, 670000, Russia

dondokova64@mail.ru

The article presents materials on the reading literacy formation of primary schoolchildren. In modern conditions, reading competence of primary schoolchildren makes it possible to lay the foundations for success in further education and future adult life. The fundamental role of reading in the modern system of education and development of schoolchildren is well known, since full-fledged literacy, erudition have always been one of the necessary components of any activity related to the perception and awareness of visual information. The development of new information technologies only increases the importance of reading in society. Mastering the techniques of working with text occurs in parallel with the development of new forms of knowledge representation related to the reading and processing of information.

Literary reading lessons provide great opportunities for the formation of reading literacy. The authors of the article share their pedagogical experience in organizing literary reading lessons in primary school. The technology of productive reading and various methodological techniques that allow you to understand the text, reflect on its content, evaluate its meaning and significance, record and use the information received, express your thoughts about what you read are described.

Keywords: reading, reader literacy of primary students, literary reading, productive reading technology, methodical techniques, competences, basic competences, pedagogical activities.

The article was submitted 02.10.2021; approved after reviewing 13.10.2021; accepted for publication 15.12.2021. 